DOI 10.37882/2500-3682.2021.06.16

\title{
К ВОПРОСУ О САМОСОЗНАНИИ ЧЕЛОВЕКА В КРИЗИСНЫХ УСЛОВИЯХ ТОРЖЕСТВА ТЕХНИЧЕСКОГО ПРОГРЕССА
}

\section{ON THE QUESTION OF HUMAN SELF-CONSCIOUSNESS IN THE CRISIS CONDITIONS OF THE TRIUMPH OF TECHNOLOGICAL PROGRESS \\ Salikh Aumed Khama-ali Salikh}

Summary: The article considers technological progress as a factor of leveling spiritual and cultural values based on the analysis of the history of the formation of the technological worldview of a person and the designation of the priority of material values in society. The author makes an attempt to identify the significant significance of the factor of awareness and acceptance of being by a person as the only possible way to preserve spiritual integrity in the conditions of the triumph of technology.

Keywords: progress, technology, being, Heidegger, Fromm, Berdyaev, spirituality, humanism.

\author{
Салих Аумед Хама-али Салих \\ ФГБОУВО «Липецкий государственный \\ технический университет» \\ Omedhamaali@yandex.ru
}

Аннотация: В статье предлагается рассмотрение технического прогресса как фактора нивелирования духовных и культурных ценностей на основе анализа истории становления технологического мировоззрения человека и обозначения приоритетности материальных ценностей в обществе. Автором делается попытка обозначить значить значимость фактора осознания и принятия личностью бытия как единственно возможного способа сохранения духовной цельности в условиях торжества техники.

Ключевые слова: прогресс, техника, бытие, Хайдеггер, Фромм, Бердяев, духовность, гуманизм.
$\Pi$ онятие прогресса на заре своего становления явно соотносилось с возможностями более продуктивного взаимодействия человека с окружающим миром, что, естественно, было возможно только в материальном формате. Поэтому технический прогресс воспринимался позитивно, поскольку позволял человеку облегчить его повседневное бытование, уменьшал количество физической нагрузки, как бы высвобождая время и силы для развития духовной составляющей отдельной личности и нравственной сферы функционирования общества. Значительную роль в положительном восприятии прогресса сыграли реальные технические изобретения, которые в период XVIII-XIX вв. изменили жизнь общества и отдельной личности, занятой в производстве материальных объектов. На закрепление идеи техники как позитивного направления развития общества повлияли также, несомненно, социальные и философские концепции того же периода, определявшие материалистические - естественнонаучные прежде - всего перспективы человечества.

Оптимистическое восприятие прогресса позволило человечеству думать и говорить о соотношении понятий прогресса духовно-нравственного и прогресса технического. Зачастую эти аспекты прогресса как явления воспринимались как амбивалентные, что позволяло использовать только понятие прогресса, без акцентуации его технического базиса. При этом даже формальное соотношение этих понятий не проводилось, поскольку философия (и, кстати, литература как сфера существования основных социально-культурных и идейно-психологических интенций) XIX века с ее направленностью на человека не допускала мысли о том, что развитие техники может в принципе не быть направленным на благо человека, а люди, формирующие технический контент бытового повседневного существования, могут быть не гуманистически направленными, поскольку развитие техники ради техники - процесс бессмысленный. (Нельзя не вспомнить разнонаправленные по идеологическим установкам, но сходные в оценке технологического прогресса произведения художественной литературы: Н.Г. Чернышевский «Что делать?», О. Ганштейн «Электрополис»). Подобное своего рода неведение, наивная вера в здравомыслие, гуманизм и духовность человечества привели к тому, что техника заняла существенную часть жизненного пространства, вытесняя постепенно духовно-нравственные составляющие бытия человека. При этом представление о постепенности данного явления около 200 лет - явно ошибочное, поскольку указанный приблизительный срок «вторжения техники в духовный мир человечества» является предельно малым в перспективе оценки существующей ныне цивилизации, тем более, что в XX-начале XXI вв. формат технического развития, довлеющего над развитием нравственным, увеличился в сотни раз благодаря появлению новых технологий, способных порождать новые технологии уже самостоятельно, без участия человеческого интеллекта. И то, что еще в середине XX в. можно было оценивать как 
оригинальные идеи писателей-фантастов (например, Айзека Азимова, Роберта Шекли, Эдварда Моргана Форстера), сегодня не просто в буквально-материальном формате стало реальностью - на уровне используемых в повседневном быту предметов, а начинает вытеснять человека как деятельное лицо из всех процессов функционирования общественных институтов. На банальном уровне это легко иллюстрируется работой компьютеризированных автоответчиков в крупных промышленных и коммерческих компаниях, которые способны не только выдавать заранее заложенный текст, но и реагировать на вопросы абонента, самостоятельно моделируя коммуникативную ситуацию и подбирая из миллионов речевых реакций-реплик наиболее подходящие. Ученые различных социальных и технологических структур обсуждают возможности использования искусственного интеллекта на всех уровнях личностного, коллективного, государственного и межгосударственного взаимодействия как позитивную перспективу, как бы в принципе вычеркивая из сферы взаимодействия (хотелось бы сказать - «общения») такие параметры, как личностное ориентирование на адресата, учет эмоционально-психологического состояния коммуникантов, моральнонравственные аспекты взаимодействия народов, культур и государств.

Именно поэтому сегодня, в связи с масштабным развитием технической стороны действительности, соотношение технического и духовно-нравственного прогресса оценивается современной социальной философией как проблема, порожденная глобальным кризисом цивилизационного развития человечества. О кризисе гуманизма как метафизической проблеме, нравственной деградации общества, трансформации гуманистических идеалов говорят современные ученые как о явлениях, получивших определенную константность и уже не полемичных [6], поскольку культура не может строиться на принципах исключительного приоритета рационального начала над духовным. Рационализм, требующий все большего подчинения законам технического развития и вполне объяснимого с естественнонаучных и технических позиций процесса жизненного функционирования, лишает бытие человека той самой тайны, которая, собственно, составляла (и должна составлять) основу жизни: «Универсальная рационализация, техническая организация, отвергающая таинственные основы жизни порождает утерю старого смысла жизни, тоску, склонность к самоубийству,» - писал еще Н. Бердяев [2, с. 600].

Торжество технического прогресса нивелирует значимость духовно-нравственных координат в развитии общества, что должно восприниматься именно как кризисное положение.

Общество, которое уже приобрело устойчивую характеристику как постиндустриальное, по мнению и ученых, и философов, настроено прежде всего на материальную переработку, буквальное физиологическое потребление определенных благ. Парадоксальным в данном случае является и тот факт, что в своем о стремлении к комфортному существованию человечество стало воспринимать материальное усовершенствование быта как «благо», утрачивая представление о сущностном наполнении категории блага в философско-религиозном контексте. Не затрагивая глубоко особенности современного развития и функционирования религиозных учений и их влияния на личность и общественные институты, на выстраивание отношений как внутри религиозных вероучений, так и в межконфессиональном формате, нельзя не заметить, что в контексте политических проблем, например, взаимодействия Востока и Запада, миграции и др. часто звучат обозначения «мусульманский», «христианский», но в ходе более полного погружения в ситуацию выявляются экономические и геополитические аспекты, которые превалируют над вопросами морали и нравственности (что особенно зримо выявляется в новостных текстах).

При этом взаимоотношения человека с миром - вопрос, который в процессе развития преобразованием существующих реалий мира для наиболее полного удовлетворения материально-физиологических потребностей человека. Э. Фромм считал, что человек, порожденный постиндустриальным обществом и органично существующий в системе потребительских ценностей, это особый тип технократической личности - кибернетический человек [10]. Особенностью данного типа человека является общеинтеллектуальная и техническая образованность при полной неспособности к естественным человеческим отношениям. Кибернетический человек в силу своей духовной отчужденности от природы оказывается неспособным воспринимать и достижения культуры.

Философия многих столетий размышляла над проблемой человеческого, пытаясь охарактеризовать обозначить человечность в качестве перманентного свойства личности. При этом степень человечности определялась как раз способностью разных индивидов не просто располагаться в одном социально-культурном пространстве с целью выживания, но прежде всего испытывать внутреннюю духовную потребность в совместном бытии и «со»-бытии. Однако современность, ориентированная прежде всего на развитие технологических коммуникаций, актуализирует вопрос об обособлении людей, о последовательной утрате потребности совместного бытия. Сближение отдельных индивидов между собой, личностное единение или формирование коллективного духовно-нравственного контента оценивается сегодня как устарелая форма бытования. И хотя формально взаимодействие индивидов в современных условиях проходит интенсивно, обмен информацией, в 
том числе и личного характера, имеет более активный характер, чем в предыдущем столетии, но взаимодействие строится прежде всего на прагматическом интересе. И этот прагматический интерес базируется на получении финансовой прибыли. Именно финансовое благополучие становится одной из доминирующих ценностей современного общества. В условиях трансформации ценностей формируется состояние, при котором преклонение перед финансовой прибылью оценивается как норма. Трудно спорить с тем, что стремление к материальному благополучию легитимно и является одним из фундаментальных прав личности, поскольку способность участвовать в товарно-денежных отношениях обеспечивает человеку в том числе и возможности реализации духовно-нравственных потребностей, интеллектуально-психологического развития. Однако негативным следствием пропаганды финансово-экономического состояния личности как критерия его социальной состоятельности становится то, что деньги становятся единственной целью, определяющей и оправдывающей смысл жизни и бытия. На наш взгляд, подобное отношение не соотносимо с понятием о достоинстве и гордости, а состояние личности, принимающей финансовый критерий как основной для саморазвития и самоутверждения, и общества, формирующего денежный эквивалент всех общественных установок и ценностей, можно охарактеризовать как нравственную патологию. Таким образом, формируется новый, искусственный человек, совместимый с доминирующей в современном социуме формой жизни.

Такой человек не задумывается о смысле личного бытия и, следовательно, игнорирует вопрос о сущности / целеполагании / продуктивной результативности собственной деятельности, хотя именно попытка осмысления деятельности как значимого процесса определяет «самотворящую» природу человека.

Человек, не делающий попытки осмыслить собственное предназначение и - шире - сущность собственного бытия, не способен осознать вопрос о субстанции собственной деятельности. А данный вопрос является ключевым для развития «самости» личности. В терминологии М. Хайдеггера, определяющим для выявления человека, для его выделения из общей природной материи является как раз «Dasein» («вот-бытиё» или «здесь-бытиё»), которое прежде всего формируется способностью живого существа, претендующего на звание человека, задаваться вопросами о сущности бытия [11, с. 192-220]. Несомненной гуманистичностью по отношению к человеку обладает идея М. Хайдеггера о том, что в человеке перманентно присутствует некая «бытийная понятность» или «бытийная отзывчивость» как способность человека / личности ответить на вызовы / призывы / отзвуки бытия. При этом «Dasein» тождествен духовной и нравственной сущности.
Современность заставляет задуматься о том, насколько человек, погруженный в повседневную техническую (наверное, в сегодня уже более реалистично говорить «технократическую») жизнь, способен задуматься о «Dasein» собственного бытия? Задается ли он духовно-нравственными вопросами? Способен ли воспринимать и оценивать свою деятельность как процесс, как «осуществление», а не как практико-ориентированный, прагматический результат? По мнению М. Хайдеггера, который в своих исследованиях попытался синтезировать метафизический опыт всей европейской культуры [7, с. 10], сущность деятельности заключается как раз в ее осуществлении, а не в конечном результате, на который настраивает человека современная действительность. То, что обозначается как осуществление, есть некое действие или поступок, который приводит к личность к совершенству собственного бытия, делает возможным реализацию духовного и нравственного мировоззрения человека. Таким образом, создаются условия для осуществления со-быти'я. Но человек может стать достойным подобного положения только в том случае, если он задается вопросами о смысле, сущности, судьбе своего личного бытия и бытия вообще, если смыслом его существования становится осмысление своего бытия и бытия других.

При этом ключевой позицией «осуществления» становится реализация мысли в слове. Только через слово возможно осуществление связи Бытия и бытия человека. Это единственная возможность человека не только определить истинность существующих отношений, но и обозначить отношение к собственному бытию. Значительным фактором формования личности является также осмысление отношения какого-либо человеческого бытия к другому, заключенное в «бытии-с-другим». И данное осмысление, которое должно быть реализовано в слове, морально. Нравственность в условии механического детерминизма и неосмысленности не способна иметь подлинное бытие, ибо подлинность бытия нравственности основывается на фундаменте свободного действия и свободной ответственности. Человек не может быть нравственным, либо безнравственным, если он не свободен. Хотя несвобода - аморальна. Неосмысленность отношения проистекает из того, что человек инстинктивно входит в отношение с другим, и его отношения сводятся к инстинктам и повседневным потребностям, отсюда отношение вообще стало более не человечным.

Однако нацеленность современного человека на результат деятельности определяет то, что в процессе деятельности воспроизводятся элементарные, уже давно апробированные формы, не остается пространства для создания принципиально нового. То есть жизнь человека превращается в рутину, лишенную творческого начала. В таком случае производство материального не имеет 
ничего общего с духовностью, и человек не в состоянии противостоять утверждению материального мира, материального бытия, основанных на лже-ценностях: эгоизме и сребролюбии. Единственное, что в силах человека, - это попытаться осмыслить формирующиеся угрозы, обозначить их вербально.

И прежде всего, нужно осмыслить явление техники. Еще Н. Бердяев отмечал: «Не будет преувеличением сказать, что вопрос о технике стал вопросом о судьбе человека и судьбе культуры» [1, с.3-38]. При этом философ (говоря о XIX веке!) называет технику «последней любовью человека», что является порождением века, утратившего не только религиозные, но и культурно-гуманистические приоритеты. Уверовав в «мощь и бесконечное развитие техники» [Там же], человек принял как данность возможность собственного изменения под влиянием техники. Подобное положение, казавшееся не только безобидным, но и продуктивным (ибо техника воспринималась как некое чудо в рамках обыденной действительности), в результате привело к тому, что человек по собственному желанию лишился своей свободы, подчинившись механическому миру. И хотя первоначально техника являлась продуктом деятельности человека, в результате метафизической трансформации «творец» и «творимое» поменялись ролями, человек оказался в рабстве у продукта своей деятельности, что заставило человека жить, забыв заветы отцов (как было сказано в притче М. Горького) [3, с.75-76], поскольку любая форма рабства предполагает не только материально-физическое подчинение, но и признание духовно-нравственных идеалов правящей стороны. В случае же с отношениями человека и техники, человек оказался в рабстве у механической субстанции, не имеющей в принципе каких-либо морально-нравственных основ, поэтому и человек очень быстро «забыл» о существовании «заветов отцов» - то есть традиционных гуманистических ценностей, оторвался от корней, утратил связь с Бытием.

И хотя еще М. Хайдеггер разграничивал технику и сущность техники [12, с.221-238], современный человек, не поднимающийся до осмысленного отношения собственного бытия, едва ли способен осознать, что оказался подверженным банальному влиянию техники. Техника в данном случае выступает в своей капиталистической ипостаси - служит средством преумножения капитала, в результате чего формируются условия для усугубления социального неравенства и - обобщеннее для тотальной несправедливости, поскольку техника становится определяющим фактором бытия человека. Тем самым она становится угрозой природе - не в ее материальной воплощенности, а в формате представления Бытия. И хотя техника сама по себе не отражает моральных или аморальных категорий, но ее включенность в общественные процессы, зависимость общества и, шире, Бытия от технократических тенденций современ- ности вынуждает говорить о том, что техника разрушает духовно-нравственную среду, в которой только и может реализовать человек осуществление (о чем говорилось выше). И человек не имеет возможности до конца осознать тот факт, что он сегодня не способен противиться воздействию техники на его бытие. А без осознания данного положения человек не может и переориентировать процесс технократиации в свою пользу, то есть взять контроль над техникой. В противном случае, по нашему мнению, человек сам уничтожит свое бытие и при этом будет убежден, что реализовал свое право на самоопределение в условиях легитимности.

Не имея высоких духовно-нравственных опор, позволяющих сохранить свое подлинное бытие, человек, подчиняясь влиянию техники, разрушает и свой естественно-материальный, природный мир. Еще О. Шпенглер, рассматривая технику как один из факторов разрушения культуры и истории, применял «природные» метафоры, уподобляя технику хищнику, который разрушает природную гармонию и, соответственно, человек, подчиняясь своеобразной «биологической борьбе» техники с природой, отчуждается от природы и включается процесс ее уничтожения [14]. Вопросы экологии как формы банального сохранения сферы существования человека сегодня уже не обозначаются как нуждающиеся в обсуждении, поскольку фатальное влияние человека на природу - общепризнанный факт, не только подверженный научному и общественному обсуждению, но и получивший сатирическое художественное отражение [4]. В сложившихся условиях человек, в обязанностях которого быть хранителем природы и бытия, становится разрушителем, утратившим представление нравственность [9, с. 102-134].

Нужно признать, что проблемы современного человечества не являются порождением только наших дней - они являются естественным результатом исторического преобразования человеком как материального мира, так и духовно-нравственной среды, на сущностные основы которой человек посягал в течение веков и даже тысячелетий. Ведь реализуя «материально-социальные проекты»: война, колонизация, промышленная эксплуатация природных ресурсов - человек оказывался ввергнутым в процесс разрушения ценностей. Одновременно этот процесс получал обострение именно в связи с тем, что с масштабированием материально-экономической и промышленно-технической деятельности человечество начинает искать ценностные опоры [8, с. 47-49]. В современной истории подобные кризисные периоды встречаются неоднократно, и наши дни, к сожалению, могут быть обозначены как эпоха духовнонравственного кризиса [Там же], когда отторжение традиционных ценностей разрушительно сказывается не только на метафизической, но и на чисто человеческой основе гуманизма. 
Некоторые ученые связывают потерю духовно-нравственных идеалов и ориентиров с утратой личностной, общественной, культурной идентификации. Так, связывая состояние человечества и отдельных сообществ с политологическими факторами развития цивилизации в период последнего десятилетия XX - начала XXI вв., Самюэль Хантингтон говорит о потере форматов национальной идентичности различными народами - даже теми, чье повседневное состояние отличается внешним благополучием и техническим [13, с.186]. Логично, что в обозначенных обстоятельствах сохранение духовности в принципе невозможно, поскольку духовность является результатом многовековой внутренней работы личности, ориентирующейся на общественные интенции и рецепции, на возможность соотношения своих моральных и нравственных переживаний, намерений и поступков с голосом высшего разума и высшей истины. Однако при нарушении системы идентичности происходит разрушение собственно природы человека.

Говоря о человеческой природе, мы имеем в виду высший образец человека, способного к осознанному бытию. Мы считаем возможным соотношение здесь с ницшеанской концепцией Сверхчеловека, если иметь в виду, что Сверхчеловек как форма высшего сознания и самосознания есть категория нравственная, соответ- ствующая новому уровню развития общества и бытия.

Однако современный человек не осознает «СверхЯ», то есть не способен перевоплотиться в Человека, поскольку не стремится преодолеть сложившиеся к настоящему моменту формы бытования, удовлетворяясь комфортно-технологическим существованием, принимаемым как эволюционно новый передовой этап.

Одним из наиболее ярких проявлений согласия человека с техническим диктатом (на бытовом, повседневном уровне) является восприятие жизни как системно повторяющегося, циклически работающего поиска «развлечений», что проявляется в продуктах так называемой масс-культуры [Там же]. Термин «масс-культура» используется неслучайно и внедрение его позитивной коннотации в сознание современного человека является задачей формирования потребительского общества, поскольку подлинная культура (даже на уровне использования термина) предполагает внутреннюю соотнесенность творческого процесса с Бытием, с вопросами нравственной чуткости, гармонии, осознанности красоты как категории философской. Естественно, что творчество и саморазвитие в рамках культуры противоречит задачам масс-культуры, то есть нарушает систему формирования покорного технике индивидуума.

\section{ЛИТЕРАТУРА}

1. Бердяев Н.А. Человек и машина (Проблема социологии и метафизики техники) // Путь. - 1933. - № 38. - С. 3-38.

2. Бердяев Н. Смысл творчества. Опыт оправдания человека. -М.: АСТ, Астрель, 2011. 772 с.

3. Горький М. Старуха Изергиль // Горький М. Рассказы. Пьесы - М.: Дрофа, 2004. - 480 c.

4. Зиновьев А.А. Глобальный человейник. - М.: ЭКСМО, 2006. 448 с.

5. Кривоносова Е.Э., Рудковский Э.И. Информационное общество и трансформация ценностных измерений духовного мира человека // Ученые записки Оу ВГУ им. П.М, Машерова. 2019. Т.29. С.77-82.

6. Ладыгина 0.В. Философское осмысление проблем развития современного общества в условиях глобализации. Монография. - Душанбе: РТСУ, 2015. - 131 с.

7. Нижников С.А. М. Хайдеггер: преодоление метафизики // Вестник ВятГГУ. - 2014. - №8. С.6-10.

8. Николаева И.А. Смысл жизни как системная целостность ценностных отношений и его операционализация // Психологические проблемы смысла жизни и акме. Материалы XI симпозиума / Под ред. Г.А. Вайзер, Е.Е. Вахромова. М.: Изд-во Психологического института РАО, 2006. С. 47-49.

9. Татаренко Н.А. Понятие нравственного и его интерпретация в гегелевской «Системе нравственности» // Историко-философский ежегодник. - 2019. Т.34. C.102-134.

10. Фромм Э. Анатомия человеческой деструктивности: Перевод / Авт. вступ. ст. П.С. Гуревич М: Республика, 1994. 447 с.

11. Хайдеггер М. Письмо о гуманизме // Хайдеггер М. Время и бытие: Статьи и выступления: Пер. с нем. - М.: Республика, 1993. 447 с. С. $192-220$.

12. Хайдеггер М. Вопрос о технике // Хайдеггер М. Время и бытие: Статьи и выступления: Пер. с нем.. - М.: Республика, 1993. 447 с. С. $221-238$.

13. Хантингтон С. Кто мы?: Вызовы американской национальной идентичности. - М.: АСТ,Транзиткнига, 2004. 635 с.

14. Шпенглер 0. Закат Европы. Очерки морфологии мировой истории / Пер. с нем. и примеч. И.И. Маханькова. - М., 1998. - 606 с.

15. Lion D. Information Technology and Information Society: A Response to Fincham . Cambridge: Polity Press, 1987.

16. Shatalova 0.V., Paveleva T.Yu. Semantic neutralization of current socio-political terms as a factor psychological adaptation in present-day communicative conditions // AMAZONIA investiga. 2019 . №23. V.8. 517-525 pp.

(с) Салих Аумед Хама-али Салих (Omedhamaali@yandex.ru).

Журнал «Современная наука: актуальные проблемы теории и практики» 